\title{
The Fluorescent Polydiacetylene Liposome
}

\author{
Fun-Kyung Ji, Dong June Ahn, ${ }^{\hat{\hat{T}}, *}$ and Jong-Man Kim ${ }^{*}$ \\ Deparment of Chemical Engineering, College of Engineering, Hamyang Universin, \\ I7 llaengdang-dong, Seongdong-gut, Seoul 133-791, Korea \\ "Department of Chemical and Biochemical Lngineering, Korea University, Anam-dong, Sunghtk-gu. Seoul 136-701. Korea \\ Recened February 11,2003
}

Key Words : Polydiacetylene, Biosensor, I iposome, Color change, Fluorescent monomer

Development of efficient sensors utilizing conjugated polyner as sensing matrices has gained much attention among many research scientists. ${ }^{1-11}$ Especially, polydiacetylene (PDA)-based sensors for the detection of biologically important species have been intensively investigated due to the unique color changing properties upon stimulation. ${ }^{12-27}$ Closely packed and properly designed certain diacetylenes can undergo polymerization via 1.4-addition reaction to form an ene-yne alternated polymer chain upon UV irradiation with $254 \mathrm{~nm}$ as shown in Figure 1.28-35 the resulting polydiacetylenes, if obtained under optimized conditions, appear to be intense blue color to the naked eyes. The blue-colored polydiacetylenes can be prepared in the form of liposomes in aqueous solutions or as thin films using Langmuir-Blodgett or Langmuir-Schaefer methods. The advantage of the nanostructured polydiacetylenes as biosensors comes from the fact that visible color change from blue to red occur in response to a variety of environmental perturbations, such as temperature, ${ }^{36-39} \mathrm{pH}^{40}$ and ligand-receptor interactions. $^{12-14.27}$ Many researchers have tried to understand the mechanism of the color transition. Although it is not clear, it has widely been accepted that color change is associated with a conformational change of polydiacetylene backbone. Accordingly, the polydiacetylenes in the blue form have extended conjugation of $p$-orbital in the main chain of the polymers. 'The conjugated $p$-orbitals undergo distortion by environmental stimuli, leading to partial twist

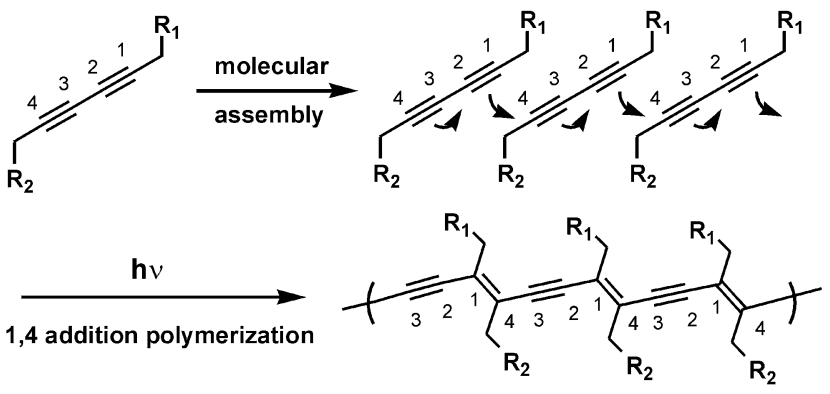

( $R_{1}=$ functionalized alkyl chain, $R_{2}=$ alkyl chain $)$

Figure I. Schematic representation of polymerization of assembled functional diacelylenes by irradiation with UV light.

"Co-Corresponding authors. Dong June Ahn (Fax: +82-2-926610I: c-mail: ahnakorca.ac.kr): Jong Man Kim (Fax: +82-22298-4101: c-mail: jmk'athanyang.ac.kr) of the $p$-orbitals. 'Thus, the dark blue color of the polymers gradually shifts to the red color depending on the amount of the stress.

One of the most commonly used matrix lipid monomer for polydiacetylene-based biosensor is 10,12-pentacosadiynoic acid ('PCDA 1) (Figure 2). The PCDA lipid monomer can readily be assembled in aqueous media in the form of polymerized liposome vesicles after UV irradiation. When indicating the lipid concentration in a liposome solution, one calculates it based on the total lipid monomers used. assuming all of the monomers are transformed into the liposome. Since it is practically impossible to directly measure the lipid concentration of polymerized diacetylene liposomes, the nominal concentration has been widely used as a standard measure, even without rigorous proof. However, in order to use such nominal concentration for the purpose of calibration of PDA-based sensors, we will need to prove most of, if not all, the l'CDA molecules assembled to bilayered liposomes in aqueous solution. This could be done by using a fluorescent lipid monomer which is newly derived from PCDA. If a liposome solution is prepared with

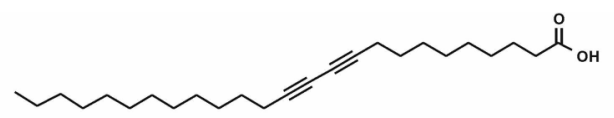

10,12-pentacosadiynoic acid (PCDA,1)

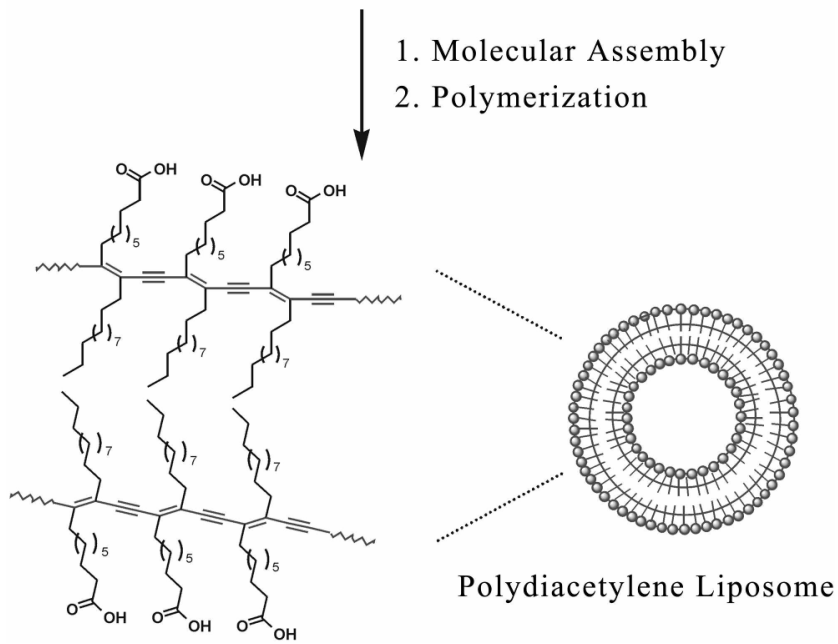

Figure 2. Schematic representation of the liposome prepared with 10.12-pentacosadiynoic acid (PCI)^, 1 ). 

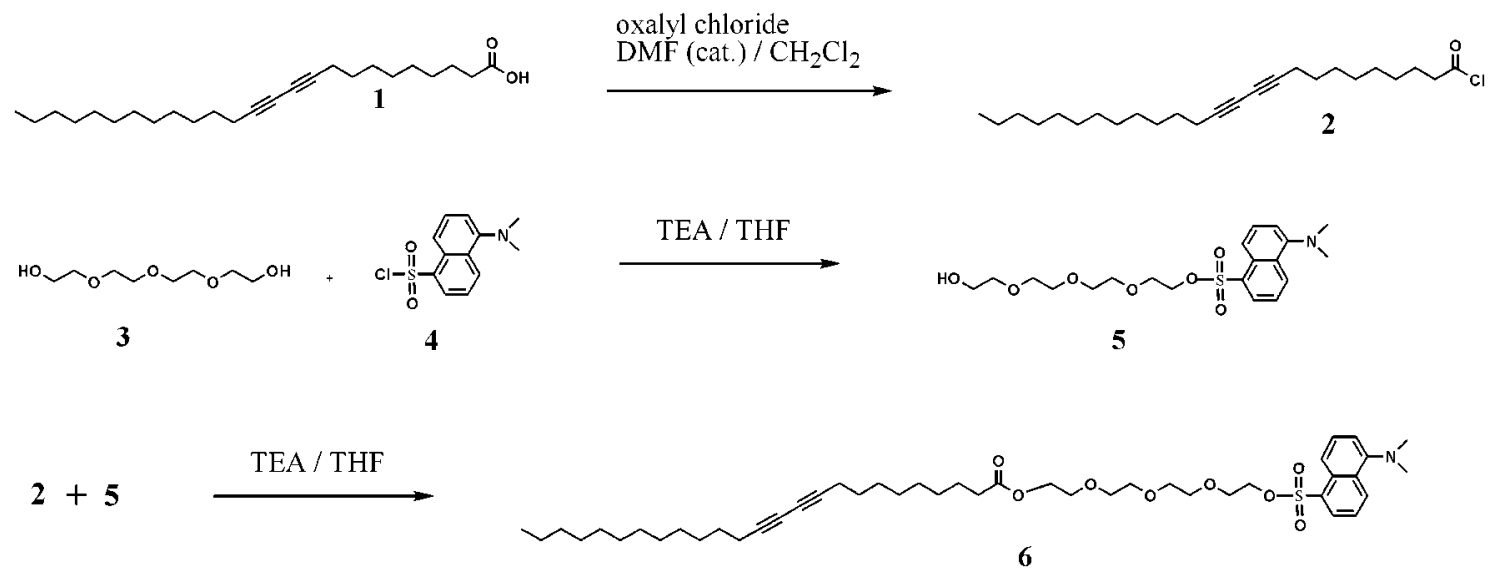

Figure 3. Synthetic procedures tor the preparation of the fluorescent diacetslene monomer 6

a mixture of a fluorescent lipid monomer and PCDA and if all of the lipid monomers are converted to liposome. we should not be able to detect fluorescence in the mother liquid after dialysis. We now report a straightfonward method for the measurement of efficiency of the formation of polymerized diacetylene liposomes with a fluorescence-labeled diacetylene monomer

\section{Results and Discussion}

The preparation of the diacetylene monomer 6 having a fluorescent head group is shown in Figure 3. Synthesis of the monomer 6 having a fllorescent head group was very straightforward. Firstly. the commercially axailable 10.12pentacosadiynoic acid (PCDA, 1) was converted to the corresponding acid chloride 2 with oxalyl chloride. Secondly, tetra(ethy lene glycol) (3) was coupled with dansyl chloride (4) to give a linker molecule with fluorescent chromophore 5. The tetra(etlylene glycol) unit was introduced to make the fluorescent head group hydrophilic. Final step of obtaining the diacety lene monomer 6 was accomplished by reacting the 10,12-pentacosadiy noic acid chloride (2) prepared as described above with the tetra(ethylene glycol) derivative having fluorescent chromophore 5 .

Having prepared the fluorescent diacetylene monomer 6. next phase of our efforts focused on the preparation of polydiacetylene liposomes with the fluorescent diacety lene monomer 6. General procedures for the preparation of polydiacety lene liposome in aqueous solution is presented in Figure 4 . In the first step, a diacetylene monomer is dissolved in chloroform in a test tube and the organic solvent is removed by purging with $\mathrm{N}$ ₹ to give a thin film of the lipids on the glass surface. Deionized water or a proper buffer is added to yield typically a total lipid concentration of $1 \mathrm{mM}$. The sample is then heated at $80^{\circ} \mathrm{C}$ for $15 \mathrm{~min}$ and sonicated for $15 \mathrm{~min}$. The resulting solution is filtered through a $0.8 \mu \mathrm{m}$ filter and the filtrate is cooled at 4 " $\mathrm{C}$ for 12 h. Polymerization is carried out at room temperature by irradiating the solution with $25+\mathrm{nm}$ UV light $\left(1 \mathrm{~mW} / \mathrm{cm}^{-}\right)$to induce conjugated backbone of altenlating double and triple bonds.

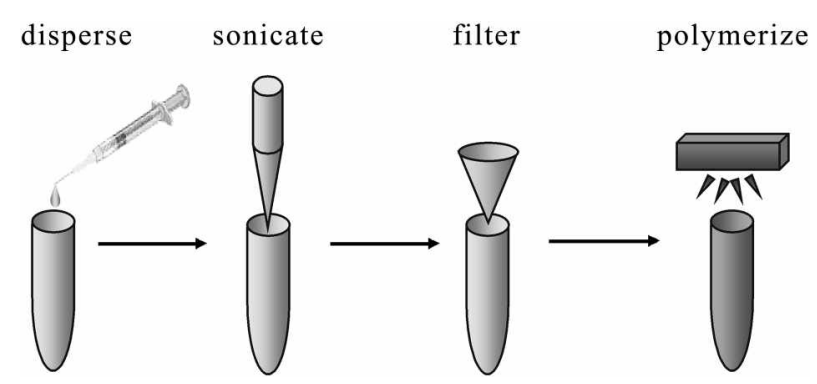

Figure 4. General procedures for the preparation of polydiacetylene liposones.

When the fluorescent diacetylene monomer 6 was subjected to above procedures. no polymerization was occurred. This is presumably due to the flexible tetra(ethylene glycol) units which prevent molecular assembly of the monomers. In general. monomers having headgroups which can not

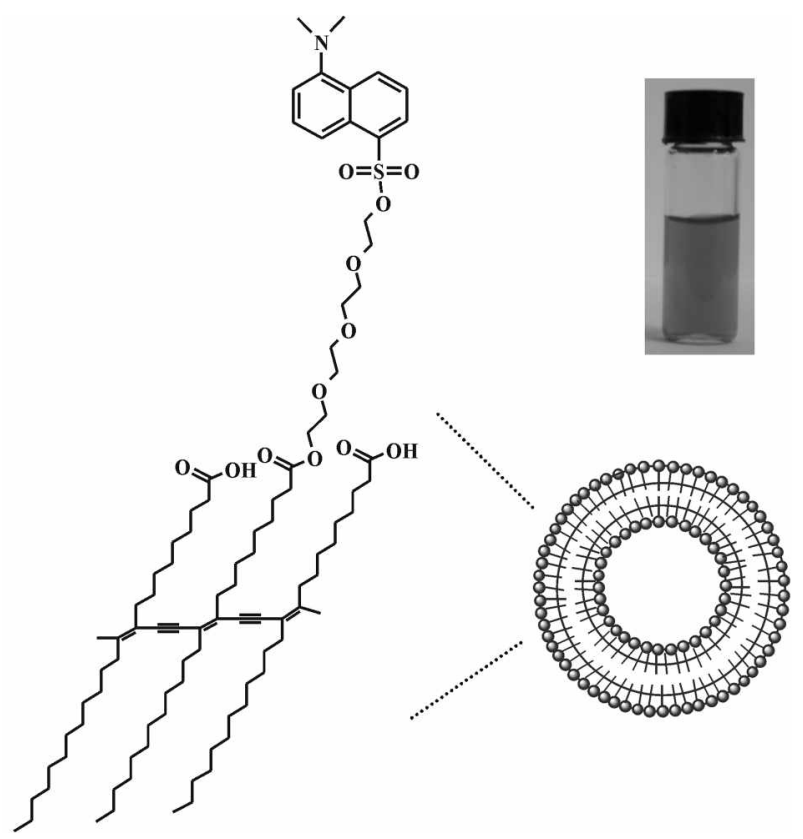

Figure 5. Schematic representation and a picture of a polydiacetyene liposome prepared with a misture of the fluorescent diacetylene 6 and PCDA 1 

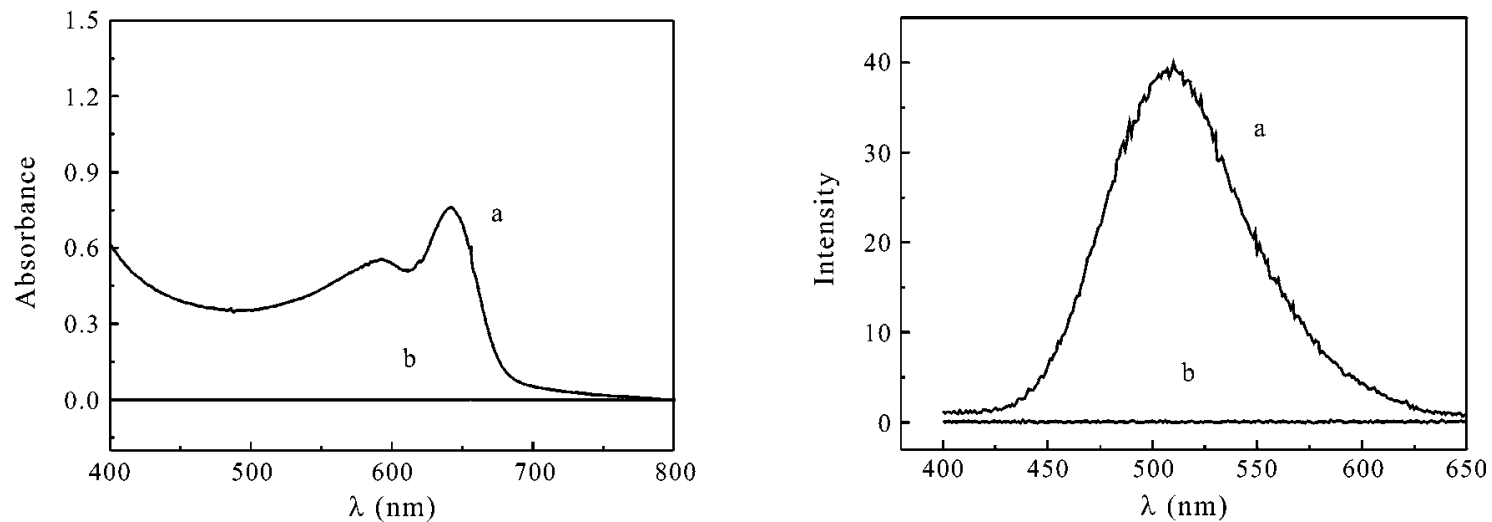

Figure 6. 'lhe visibila (lelt) and lluorescence (right) spectra of solutions inside (a) and outside (b) membrane alter dialysis (excitation at 340 $11 \mathrm{~m}$ for fluorescence spectra).

form intermolecular lỵdrogen bonding tend not to generate stable polydiacety lene liposomes. Therefore. the fluorescent diacetylene monomer 6 was mixed with 10.12-pentacosadiy noic acid (PCDA. 1) which is widely used as matrix lipid monomer and known to form stable liposome vesicles.' The mixture of the fluorescent monomer 6 and PCDA 1 (monomer 6: PCDA = 3: 7. molar ratio) was dissolved in cluloroform and followed routine protocols for polydiacetylene vesicle fomation. The liposome resicles prepared showed intensive blue color and Figure 5 presents a schematic picture of the resulting polydiacety lene vesicle.

ln order to in estigate how efficiently the fluorescent diacetylene lipid monomers were incorporated into the matrix lipid 1 for liposome formation. the blue-colored liposome solution was dialyzed by using a membrane (cutoff molecular weight: 10.000 ) against ample amount of deionized water. Since the diameters of polydiacetylene vesicles. in general. are above $100 \mathrm{~nm}$. the polymerized vesicles should not be able to penetrate the membrane. If there are any fluorescent monomers which were not participated in the liposome formation. we should be able to detect them in mother liquid because they can cross the membrane freely: Accordingly, we took both visible and fluorescence spectra of the solutions inside and outside the membrane after dialysis (Figure 6). As can be seen from the inspection of the spectra. the solutions inside the membrane show a typical visible spectnum for the blue-colored polydiacetylene liposome (Figure 6. left (a)) and a fluorescence spectrum for the dansyl group (Figure 6, right (a)). No absorbance or emission peaks were observed in the mother liquid outside the membrane. These observations demonstrate that most. if not all of the fluorescent diacety lene monomers 6 were incorporated into the liposome vesicles.

\section{Conchusions}

We have prepared a diacetylene lipid with a strongly fluorescent head group. The fluorescent monomer was readily synthesized from the commercially asailable 10.12pentacosadiynoic acid (1). The fluorescent monomer was mixed with the matrix lipid 1 and subjected to routine procedures for the formation of polydiacetylene liposomes. Irradiation of the resulting liposomes with $254 \mathrm{~nm} U \mathrm{~V}$ light induced intemolecular addition polymerization and generated blue-colored polydiacetylene vesicles. Dialy sis of the obtained liposomes with a membrane of molecular weight cut-off of 10,000 was performed. No fluorescent monomers were detected in the mother liquid after dialysis. confirming most of the fluorescent monomers were involved in the liposome formation. This is the first experimental proof using a fluorescent lipid monomer that the 10.12 pentacosadiynoic acid and its structurally analogous derivatives can be efficiently transformed into polydiacetylene liposomes. Thus, the results described above should give useful information on the development of polydiacetylenebased selssors.

\section{Experimental Section}

General. 10,12-Pentacosadiynoic acid (PCDA) was obtained from GFS Chemicals. Dansyl chloride. triethylanune (TEA). tetra (ethylene glycol), oxalyl chloride and +-dimethylamunopyridine were purchased from Aldrich Chenucal Co. UV-vis spectra were measured using an Agilent $8453 \mathrm{E}$ spectrosphotometer. Fluorescence spectra were obtained with a Shimadzu RF-530l spectrofluorophotometer. ' $H$ and ${ }^{13} \mathrm{C}$ NMR spectra were recorded using a Varian $300 \mathrm{NMR}$ spectrophotometer.

Synthesis of the fluorescent lipid monomer 6. Oxalyl chloride $(0.6+$ g. $5.08 \mathrm{mmol})$ was added dropwise to the solution of $10.12-$ pentcosadiynoic acid ( $1.00 \mathrm{~g} .2 .5+\mathrm{mmol}$ ) in $20 \mathrm{~mL}$ of methylene chloride. After stirring the resulting solution for $\mathrm{l} h$. a drop of DMF was added to complete the reaction. The solution was stirred for another $3 \mathrm{~h}$ and concentrated in racto to give the acid chloride 2 which was used for the next reaction without further purification.

Triethylamine $(0.7+\mathrm{g} .7 .31 \mathrm{mmol})$ and dansyl chloride (1.65 g. $6.12 \mathrm{mmol}$ ) were added to a solution of tetra (ethylene glycol) (4.77 g. $44.48 \mathrm{mmol})$ in $50 \mathrm{~mL}$ of THF. After stirring overnight. the mixture was concentrated in vacto and the residue was subjected to silica gel column chromatography (ethyl acetate) to give $1.64 \mathrm{~g}(62 \%)$ of the 
highly fluorescent intenmediate 5 .

The acid $2(0.88$ g. 2.23 munol) prepared as described above and trietly lamine $(0.28 \mathrm{~g} .2 .79 \mathrm{mmol})$ was added to a solution of internediate $5(0.80 \mathrm{~g}, 1.86 \mathrm{mmol})$ in THF. After stiming ovemight at room temperature. the mixture was concentrated to give a residue which was subjected to silica gel column chromatography $(50 \%$ hexane-ethyl acetate to $10 \%$ chloroform-methanol) to yield $0.38 \mathrm{~g}(26 \%)$ of the desired fluorescent monomer 6. ${ }^{\mathrm{H}} \mathrm{H}$ NMR $(300 \mathrm{MHz}$. $\left.\mathrm{CDCl}_{3}\right) \delta 0.88(\mathrm{t} .3 \mathrm{H}), 1.20-1.60(32 \mathrm{H}), 2.23(\mathrm{t} . \mathrm{H}), 2.31(\mathrm{t}$. $3 \mathrm{H}) .2 .89$ (s. $6 \mathrm{H}) .3 .46-3.69$ (1n. $12 \mathrm{H}), 4.14$ (t. $2 \mathrm{H}) .4 .12$ (t. $2 \mathrm{H}) .7 .19-8.61(6 \mathrm{H}):{ }^{13} \mathrm{C}$ NMR $\left(75 \mathrm{MHz} . \mathrm{CDCl}_{3}\right): \delta 14.1$. 19.2. 22.7. 24.8. 28.3, 28.9, 29.1, 29.6, 31.9, 34.2, 45.4.63.3, 65.2. 68.6. 69.2. 69.5. 70.4, 115.5, 119.6. 123.1. 128.6. $129.8,129.9,130.5,131.3,131.5,151.7 .173 .8$.

Preparation of liposome. A mixture containing the fluorescent diacetylene monomer 6 and 10.12-pentacosadiynoic acid 1 (6:1 $=3: 7$ molar ratio $)$ was dissolved in clloroform in a test tube. The solvent was evaporated by a stream of $\mathrm{N}_{2}$ gas and deionized water was added to the test tube to give the desired concentration of lipid ( $1 \mathrm{mM})$. The resultant suspension was sonicated (Fisher Sonic dismembrator model 550 ) at a temperature of around $80^{\circ} \mathrm{C}$. Following sonication. the solution was filtered to remove dispersed lipid aggregates by using $0.8 \mu \mathrm{m}$ filter and cooled at 4 " $\mathrm{C}$ ovemight. Polymerized diacety lene liposomes were prepared by UV irradiation ( $\left.1 \mathrm{~mW} / \mathrm{cm}^{-}\right)$with $254 \mathrm{~lm}$ for 10 minintes. Dialysis of the liposome was carried out with a membrane (Miv cut-off: 10,000$)$ against deionized water.

Acknowledgments. Financial support for this research was provided by the Center for Ultramicrochemical Process Systems sponsored by KOSEF. We also thank Ministry of Information and Communication for financial support through IMT2000 program.

\section{References}

1. Okada, S.: Peng, S.: Sperak, W.; Charveh, D. I. Acc. Chem. Res. 1998, 31, 229

2. Wang. B.: Wasiclowski, M. R. J. Am. Chem. Soc. 1997, 119, 12

3. MeCullowgh. R. D.: Willians. S. l'. J. im (Them. Soc. 1993. $1 / 5$. 12214 .

4. Bäuerle. l:: Scheib. S. idv . Hater: 1993. 5. 848.

5. Shoji, F.: Freund, M. S. J.Am. Chem. Soc. 2002, 12t, 12486

6. MeQuade, D. T.: Pullen, A. F.: Swager. T. M. Chrm. Rev: 2000. 100.2537

7. Cassagnean. Ta Caruso. F, idw . Ifater 2002, H. 1620.

8. DiCesare. N.: l'into. M. R.: Sclanze. K. S.: Lakowicz. J. R.
Langmir 2002. 18. 7785

9. Song. X.: Wann. H.-L.: Shi. J.: Park. J-W.: Swanson. B. I. Chom. Mater: 2002. 14. 2342

10. Korri-Youssouti, I1.: Yassar A. Biomechomolectes 2001. 2. 58.

11. Swager. T. M. Acc. Chem. Res 1998. 31. 20 l.

12. Okada, S. Y: Jelinek. R.: Charych. D. Angen: Chem. Int Ed. 1999. 38.655

13. Charych. D. H.: Cheng. Q.: Reichert. A.: Kuziemko. G... Stroh. M.: Nagy. J. O.: Sperak. W.: Stevens. R. C. (7om. Biol, 1996. 3 . 113

14. Cheng. Q.: Stevens. R. C. fth: 1/ater. 1997,9,481.

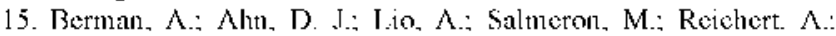
Charych. D. Science 1995. 269.515

16. Jonas. U.: Shah. K.: Norvez. S.: Charych. D. H.J.tm. Chem. Soc. 1999. 121.4580.

17. Kolushera, S.: Shahal, T.: Jelinck. R. J. Am. Chem. Soc. 2000. 122.776 .

18. Okada. S.: Peng. S.: Sperak. W.: Charych. D. Ace. Chem. Res. 1998. 31.229.

19. P'an. J, J.: Charycli. D, Iangmuir 1997. 13. 1365.

20. Huo. Q.: Russell. K. C.: Leblanc. R. M. Iangmair 1999. 15. 3972.

21. Ma. 7.: I.i, J.: I.iu, M.: Can, J.: 7ou. 7..: Tu. J.: Jiang, I. J. Am. Chem. Soc: 1998. 120,12678.

22. Kolushera, S.: Kafir, R.: Katz. M.: Jelinek. R. J. Am. Chem. S'ox. 2001. 123.417

23. Jelinek. R. Drag Develop. Res. 2000. 50. 497.

24. Kolushera. S.: Shahal. T.: Jelinek. R. Biochemistry 2000. 39. 15851

25. Kim, J-M.: Chac. F. II.: I.ce. G. S.: Shim. II. Y.: Chang. T. F.: $\Lambda$ hn, K.-D.: Ahn, D. I. J. Am. Chem. Soc, accepted.

26. Kim. J.-M.: Chang. E.-J.: Park. B.-J.: Kong. S.-S.: Suh. D. H.: Ahr. D.-I. Wacomolecules. submitted

27. Cho. J.-1.: Woo. S.-M.: Ahn. D. J.: Ahn. K.-D.: Lee. H.: Kim. J-M. Chem. Le'll. 2003, 32, 282 .

28. Chu, B.: Xu. R. Acc. Chem. Res. 1991, 24, 384.

29. Iluo, Q: Russell, K. C.: I.cblanc. R. M. Lommmir 1999, 15. 3972.

30. Sarkar. A.: Okada. S.: Nakanishi. H.: Matsuda. H. Wacromolecules 1998.31 .9174

31. Britl. D. W.: Holmann. U. G.: Möbius. D.: Hell. S. W. Lamgmair 2001, 17. 3757

32. Morigaki, K.: Baumgart, T.: Ottenhäusser. A.: Knoll, W. Anger. Chem. Int. Ed. 2001, 40. 172

33. Kim. T. S.: Chan. K. C.: Crook. R. M. J. Lm. Chen Soc 1997. 119. 189

34. Lee. D.-C.: Sahoo. S. K.: Cholli. A. L.: Sandman. D. J. Hacromolecules 2002, 35. 4.347.

35. Kochorst. R. B. M.: Fokkink, R. G.: Stuart. M. C.: 7uillot.' II. Studhölter. F. I. R. Hacromolecules 2002. 35. +226 .

36. Beckham. H. W.: Rubner. M. F. Macmmolectules 1993. 26. 5198.

37. Hankin. S. H. W. Donney. M. J.: Sandman. D. J. Polmmer 1992. 33.5098

38. Singh, A. Thompson. R. B.: Schnur, I. M. J. Am. Chem Soc. 1986, 108,2785

39. Chance. R. R.: Batughman. R. H.: Müller. H.: Eckhardt. C. J. J. (Tem Phs 1977.67.3616.

40. Cheng. Q.: Stevens. R. C. Jangmit 1998. It. 1974. 